\title{
El espacio vivido como eje articulador del binomio tiempo-narración
}

\author{
Lourdes Roca*
}

\author{
Al pasado lo podemos significar solamente en \\ imágenes que, \\ localizadas en el espacio, \\ remiten a lo que se encuentra fuera de ellas, \\ en el tiempo. (...) \\ Los iconos de la memoria, que son metáforas que \\ ocupan su lugar \\ $y$ resisten al tiempo, velan ausencias. \\ La retórica es arte de la metáfora, pero la disciplina \\ que ella enseña, \\ el arte de la memoria, es arte del icono. \\ Hay que aprender a hablar en iconos para hacer \\ la buena bistoria. \\ Georg Ekckhoff
}

EN UN MOMENTO COYUNTURAL como el que representó entre 1996 y 1997 el proceso privatizador de los Ferrocarriles Nacionales de México, - también llamados Los Nacionales de México con actitud de orgullo -, una etnografía de vida de un ferrocarrilero se presentaba como un mundo de creaciones y representaciones muy interesantes de analizar

* Instituto Mora - México 
desde la mirada antropológica para entender mejor el imaginario rielero. Salvador Núñez Hernández, ferrocarrilero durante casi cincuenta años en diferentes puntos de la república mexicana, y durante los últimos veinticinco en la Estación de Cima, ubicada en los límites del Distrito Federal con el Estado de Morelos, con una gran capacidad de observación y reflexión, constituía desde un inicio un sujeto clave para este tipo de investigación etnográfica con la que me proponía analizar y reinterpretar cómo el trabajo y los espacios condicionan una trayectoria de vida: experiencias e identidades.

Con todo y su rezago, con todo y su reciente privatización, en el imaginario colectivo de la gran mayoría está presente el ferrocarril: son estos recuerdos y sus representaciones los que observé y analicé aquí. Del gremio rielero se distingue el arraigado orgullo al que ni la liquidación o jubilación forzadas parecen poder borrar; desde el quehacer periodístico el ferrocarril destaca como uno de los temas protagonistas del acontecer noticioso y, por tanto, ampliamente cubierto también por fotoreporteros y cinereporteros; y desde el ámbito artístico, sobre todo desde la cultura popular aunque también desde las elites, resulta objeto constante de creaciones y representaciones: importantes obras literarias, tanto testimoniales como noveladas; inmortales corridos compuestos por el imaginario popular; y reveladores registros tanto fotográficos como fílmicos y videográficos que despliegan a nuestros ojos esa otra historia no oficial del ferrocarril.

Sin pretender ser una historia del ferrocarril, el estudio aquí referido constituye una historia de lo que éste ha representado para la gente; por ello la memoria y la producción cultural visual fueron los principales referentes de los que se nutrió esta investigación, que puso la atención en el estudio del ser humano en su perspectiva cultural, entendiendo la cultura como todo sistema de conocimiento que nos proporciona un modelo de realidad con el cual damos sentido a nuestro comportamiento. Si bien en este artículo no se darán a conocer los resultados de la investigación, que pueden consultarse en las publicaciones que ya los contienen (Roca, 2000a y Roca, 2000b), sí considero importantes algunas reflexiones que quiero aquí destacar y que surgieron al final del trabajo.

El periodo trabajado está enmarcado entre las coyunturas de un doble principio y un doble fin que corren paralelos: parto de la década 
de los años treinta, en que el ferrocarril es nacionalizado ${ }^{1}$, y nace Salvador, cuya vida protagoniza esta historia, para llegar a la década de los años noventa, en que se privatiza el ferrocarril y es clausurada la línea C, México-Balsas, donde él trabajó los últimos veinticinco años, viéndose obligado a jubilarse con anticipación en julio de 1997. Pero veamos por lo pronto una breve semblanza de la misma.

Salvador, originario del norte, con una identidad definida de inicio como tal, - nacido cerca de Torreón, Coahuila (o posiblemente sólo registrado ahí, porque puede haber nacido uno o dos años antes en Vanegas, San Luis Potosí, como recuerda Don Abundio Hernández, tío materno de Salvador) -, constituye un sujeto histórico y social cuyo testimonio considero definitivo para una investigación desde un principio concebida para estudiar la cultura ferrocarrilera mexicana a través de una identidad construida por la movilidad y los procesos de adaptación experimentados por una trayectoria de vida rielera como puede ser la de un jefe de estación. El "Jefe", como es conocido en un radio de más de treinta kilómetros, tenía alrededor de 65 años cuando inició la investigación y trabajó desde los 14 en Ferrocarriles Nacionales de México, primero como chicharo $^{2}$ y ayudante en las cuadrillas, y como telegrafista y jefe de estación después en diferentes estados. Participó en el Movimiento Ferrocarrilero y por vallejista ${ }^{3}$ estuvo encarcelado durante siete meses en 1959. Estudió inglés en México y Estados Unidos, a donde viajó y residió periódicamente durante tres décadas, por lo que combinaba por temporadas el oficio de rielero con el de profesor de inglés.

1 Nacionalizado en el sentido de que empieza a funcionar con capital del país, ya que Ferrocarriles Nacionales de México se crea desde 1908, pero hasta 1937 estuvo en manos de capital extranjero.

2 El chícharo era el ayudante del jefe de estación. Esta figura de suma importancia para comprender el proceso de formación de un jefe de estación, ya que los cursos que realizaban para titularse primero como telegrafistas y ya después como jefes, tenían como principal finalidad la superación de los exámenes que permitían los títulos respectivos, pero el aprendizaje real se conseguía chichareando, - o como se acostumbra a decir "se hicieron con la práctica" -, aprendiendo todas las labores que se hacían en la estación: desde cargar bultos y boletearlos, hasta vender pasajes, atender el telégrafo o llevar la contabilidad.

3 Participante activo en el Movimiento Ferrocarrilero encabezado por Demetrio Vallejo entre 1958 y 1959, con importantes efectos a nivel nacional en el principal reclamo de democracia sindical al interior de este gremio. 
Su padre fue también rielero, en las cuadrillas de Ferrocarriles Nacionales de México (FNM), su hermano conductor de trenes y su madre maestra.

De 1972 a 1997 estuvo a cargo de la estación Cima, que formó parte del Distrito de Tres Cumbres, ubicada en el Distrito Federal, casi limitando con el estado de Morelos, una estación a tres mil metros de altitud que nadie más quería atender - con un clima muy riguroso y sin las instalaciones mínimas de agua, drenaje ni luz -, donde trabajaba de día y de noche y con el telégrafo como principal herramienta, ya que la radio, sea por falta de baterías o por problemas de recepción debidos a la topografía de la zona, rara vez funcionaba.

El área en que se circunscribe esta estación que con los años se ha convertido en su lugar de residencia, fue ampliamente devastada en el primer tercio de este siglo por la tala de árboles, acabando con gran parte del bosque de los alrededores del "Cerro Pelado", para abastecer con madera a diversas fábricas y particulares del Distrito Federal. Ubicada en el punto más alto de vía entre la Ciudad de México y Cuernavaca - estratégico durante la Revolución para controlar la vía de ambos estados -, e ideada como estación donde subir el flete por etapas, librando así la llamada "pendiente gobernadora", para luego bajar con todo el flete ahí depositado, ${ }^{4}$ Cima fue en un principio el lugar de asentamiento de los leñadores encargados de la tala, ya que a través del ferrocarril se trasladaba gran parte de la madera. ${ }^{5}$

Próximo a cumplir cincuenta años trabajando para la empresa y cerca de alcanzar su jubilación, en 1996, en pleno proceso de privatización de los Ferrocarriles Nacionales de México, aumentaron los rumores de clausura de la línea $C$, a la que correspondía la estación de Cima, lo que provocó que me planteara realizar este estudio: el fin de su trayectoria laboral parecía ser el fin de FNM, y viceversa. De tal

4 Incluso cuando se subían grandes cargas, se acostumbraba a integrar una "ayudadora" (o máquina extra) que, una vez depositado el flete en Cima, regresaba, dejando que el viaje de bajada continuara ya con una sola máquina.

5 Al respecto, ha sido muy interesante el testimonio de un viejo "talamonte", Santiago Cervantes, que vivió en Cima toda su infancia y adolescencia, y que hoy habita en Parres, el pueblo más cercano a Cima, originado con la donación del ejido que les hizo Lázaro Cárdenas en 1937. 
manera que me interesó desarrollar este vínculo entre la biografía individual y las características estructurales de la situación histórica; es decir, unos años de vida del país y del ferrocarril, reflejados en las experiencias de un individuo. He ahí precisamente la importancia del periodo trabajado, 1937-1997, ya que coincide con un doble comienzo y un doble final: desde la expropiación de Ferrocarriles Nacionales de México y su consecuente expansión y modernización, hasta su inminente privatización; desde los primeros años de Salvador hasta su jubilación.

Pero dejando por lo pronto hasta aquí esta somera presentación del protagonista de esta etnografía, vale la pena recalcar algunas otras particularidades de este trabajo, a propósito de la otra fuente de investigación que privilegié: la visual y audiovisual, que aquí exigía el análisis de la imagen en una forma mucho más minuciosa que otro tipo de estudio en el que quizá se recurra a la imagen pero como elemento secundario y a nivel ilustrativo.

Con el propósito desde un inicio de realizar un documental en video a partir de esta investigación, los materiales gráficos, sobre todo fotográficos y fílmicos, se convirtieron en la otra fuente principal de investigación, junto con los testimonios orales recabados. La investigación iconográfica realizada contempló la fotografía, pero se centró sobre todo en el cine, tanto documental como de ficción (Roca, 2000b), buscando desentrañar algunas características fundamentales de las representaciones que se han creado y recreado del ferrocarril a través del medio audiovisual, con la idea inicial de que coinciden en varios aspectos con las que prevalecen en la memoria colectiva del gremio.

La historia gráfica ha sido el patito feo de la historia, como insiste en recordarnos constantemente John Mraz (1993), por lo que una de las principales intenciones de este proyecto es reivindicarla, por toda aquella información e interpretación de la realidad que puede aportar, ausente en las fuentes escritas o verbales. ${ }^{6}$ Porque la imagen, sea fija o

6 De ahí que los archivos consultados, además de los de Ferrocarriles Nacionales de México (FNM), el Archivo General de la Nación (AGN) y el archivo del Registro Agrario Nacional (RAN), sean también fotográficos y audiovisuales, como los de la Fototeca del Instituto Nacional de Antropología e Historia (INAH), los Fondos Hermanos Mayo y Enrique Díaz del AGN, la Fototeca del Museo de Ferrocarriles Nacionales de México, la Filmoteca de la UNAM, y algunas colecciones particulares. 
en movimiento, nos revela en el quehacer de la investigación formas sociales y culturales vinculadas a la vida cotidiana, el trabajo, las relaciones laborales, las relaciones entre clases, razas, sexos y generaciones, las transformaciones del espacio y el entorno urbano, las ideas y mentalidades, los usos y costumbres, las particularidades de los oficios, y un largo etcétera que se enriquece con cada estudio en el que hacemos uso de ella como fuente de análisis (Roca, 2000b). Incluso cada vez se hace más hincapié en las grandes aportaciones que puede representar para la propia historia oral la utilización de fotografías u otros objetos que despliegan el recuerdo de temas y vivencias a menudo olvidados. Esta metodología revierte curiosamente los beneficios, ya que al igual que puede enriquecer el testimonio oral, éste, a su vez, puede ofrecer muchas más posibilidades de lectura de la propia imagen.

Contra el extendido uso que los medios visuales y audiovisuales han hecho de la imagen de tantas épocas y espacios, para ilustrar o rellenar, sin ningún tipo de rigor ni respeto siquiera al momento de su creación ni al autor, debemos abogar desde la investigación por un uso autoral, ${ }^{7}$ comprometido, respetuoso y sobre todo inteligente de toda la imagen a la que recurrimos, ya sea como fuente, ya sea como medio de divulgación. El trabajo de divulgación histórica audiovisual siempre enriquece la propia investigación: se detectan con mayor claridad lagunas que todavía pueda tener e implica todo un reto de sistematización de la información y del material recabado. ${ }^{8}$

De esta manera, con un interés particular por trabajar la construcción de identidades a partir de la memoria y la imagen, el análisis de esta historia se centró en la revisión detallada de las relaciones de Salvador con los espacios y el trabajo, para revelar no una, sino una serie de identidades que emergen y se desdoblan de manera permanente en el suje-

7 Donde al utilizar imágenes como fuentes seamos tan rigurosos citando su origen y autor, como lo somos citando documentos escritos. Para ampliar la información sobre el uso de la imagen en antropología social (Coradini y Roca, 2000, p. 251-72).

8 Como alguna vez dijo Duby a raíz de la producción de la serie de televisión basada en su libro El tiempo de las catedrales, "tenía la impresión de estar descubriendo todas aquellas obras de arte de las que creía no ignorar ningún detalle. La cámara las había captado desde un ángulo inesperado. Además había recogido a su paso cantidad de imágenes con las que no contaba. (...) No era una mera adaptación, sino una verdadera creación" (Duby, 1992, p. 147-8). 
to de estudio. A través de una constante movilidad, Salvador nunca ha dejado de viajar, física y mentalmente, por México y Estados Unidos, su historia y su cultura; por lo que entre los principales ejes constructores de esta experiencia vital, aparecían de inicio una enorme curiosidad por descubrir y aprender, una gran capacidad de adaptación y hasta mimetización, una particular fascinación por vivir la vida, un gran sentido del humor y un fluido manejo del inglés, que él considera le abrió tantas puertas. Así es como a partir de numerosos encuentros y bifurcaciones, se construye y reconstruye esta vida de manera permanente, conduciéndolo por cuantiosos espacios, permitiéndole la convivencia con las más disímbolas personas y alimentándose de los más diversos conocimientos encontrados en el camino.

"Quizás la más sorprendente característica del ser humano sea su capacidad de crear, a partir de sus inquietudes, de sus pasiones y de las adversidades del medio, innumerables y plásticas formas de adecuación y adaptación” (Lizarraga, 1992, p. 254). De ahí el interés por partir del cotidiano trabajo de campo con Salvador, para después ir integrando las diversas fuentes analizadas que me permitieron construir esta etnografía: su testimonio de vida, el trabajo de observación participante, una gran variedad de documentos fílmicos y fotográficos, y los otros testimonios orales que surgieron a partir de su trayectoria vital.

Desde luego que los distintos tiempos en los que se enmarca esta historia de vida representaban uno de los retos de este estudio, de ahí la importancia de un análisis histórico; pero los diferentes espacios por los que se transita en ella, que de hecho rigen mucho más la narración de Salvador que los tiempos, implicaban un reto mayor: la observación y el análisis antropológicos, cuyas herramientas, postulados y reflexiones teóricas me permitieron encontrar y construir otras versiones e interpretaciones más cercanas a los estudios antropológicos sobre cultura popular, cultura obrera, imaginario, representaciones e identidades colectivas.

Fue a partir de esta cotidiana dinámica de observación como fue iniciando un proceso de deconstrucción detallada de esta historia de vida que a primera vista se presentaba tan rica pero a la vez tan compleja y para mí a veces hasta enredosa, debido a la gran movilidad de su trayectoria, que lo llevó a atender más de treinta estaciones a lo largo de diferentes divisiones de ocho estados del norte y centro del país. Fue 
con base en esta deconstrucción pormenorizada cuando pude comenzar a entender para después esforzarme en reconstruir esta etnografía de vida, pero no a partir de una recolección de anécdotas o sucesos en la vida de Salvador, sino a través de una narración que buscaba los hilos conductores o leitmotivs que habían ido otorgando sentido a sus experiencias de vida.

Y en primer lugar tenía como fuente el propio relato, que genera a la vez identificación y diferenciación, gestado en una situación particular: era él relatándome su vida a mí en espacios y momentos de convivencia común. Su misma historia, contada a otra persona, no hubiera sido la misma (valga la redundancia); porque aunque la materia prima de la historia de vida es la memoria, que a través de imágenes-recuerdo y procesos reflexivos construye sentido, no hay que olvidar que siempre estará implícita la dialéctica provocada por la situación de encuentro y comunicación que caracteriza a la misma producción de la historia de vida frente a otro.

Lo que fundamentalmente sentí cuando esta experiencia de convivencia con Salvador comenzó a convertirse en un proyecto de investigación fue que la integración del sujeto en el proceso de investigación, conocida como investigación social de segundo orden, era lo que me apasionaba. Es decir, un tipo de investigación donde no iba a descubrir verdades acabadas, sino a reconstruir con el sujeto de estudio sus experiencias de vida a partir del pensamiento, de la reflexión, dejando atrás el presupuesto de objetividad que ha imperado tanto tiempo en las ciencias sociales - donde el sujeto está separado del objeto, y por tanto se elimina toda huella del sujeto al investigarlo como objeto -, para adoptar el presupuesto de reflexividad, donde el sujeto ya no está separado del objeto, quedando siempre necesariamente huellas del sujeto, porque el objeto es producto de la actividad objetivadora del sujeto (Ibáñez, 1994).

Por otro lado, partiendo de la idea de que nuestro mundo lo construimos a partir de nuestras capacidades perceptivas y expresivas, me propuse pensar mucho más acerca de lo que Salvador me contaba, a partir de la reflexión sobre la narración que iba construyendo con base en sus experiencias perceptivas y su gran capacidad crítica a la hora de comunicarlas. Porque los seres vivos construimos mundos reales, pero los seres hablantes construimos además mundos imaginarios y simbó- 
licos, donde no sólo está lo actual o lo que acontece, sino lo virtual, lo posible o lo que puede acontecer. Esto era lo que me interesaba explorar y repensar aquí.

Con este propósito entré al remolino, al bucle o a la espiral que caracteriza al sistema social como un sistema abierto que permanentemente busca nuevos fines, porque en última instancia sólo se reproduce cambiando. Como dice Morin, "si parto del sistema auto-eco-organizador y lo remonto, de complejidad en complejidad, llego finalmente a un sujeto reflexivo que no es otro que yo mismo que trato de pensar la relación sujeto-objeto. E inversamente, si yo parto de ese sujeto reflexivo para encontrar su fundamento o, al menos su origen, encuentro mi sociedad, la historia de esa sociedad en la evolución de la humanidad, el hombre auto-eco-organizador" (Morin, 1996, p. 69).

Más allá del reduccionismo, que sólo ve las partes, y el holismo que no ve más que el todo, ésta constituye una búsqueda para poder pensar cómo los individuos producen a la sociedad que produce a los individuos, con base en que todo está en la parte que está en el todo, principio hologramático que para mí explica a manera de espejo el otro principio fundamental que nos ayuda a pensar la complejidad, el recursivo, equivalente a la figura del bucle o la espiral, que a su vez permite ver que los productos y efectos son también causas y productores de aquello que los produce. Juntos, estos dos principios que son cada uno una cara de la misma moneda, me ayudan a comprender el tercero que Morin considera para pensar la complejidad y que para mí resulta quizá el más críptico: el dialógico, que permite mantener la dualidad en el seno de la unidad porque asocia dos términos a la vez complementarios y antagonistas.

La perspectiva utilizada tiene carácter de hermenéutica y de fenomenológica, puesto que contempla el análisis sociohistórico, el análisis formal o discursivo y la interpretación-reinterpretación constantes, para poder reconstruir las condiciones sociales e históricas de la producción, la circulación y la recepción de las formas simbólicas, no con el afán de revisar el pasado para explicar el presente, sino de partir de la cotidianidad pasada y presente para ver qué sigue siendo actual y cómo se recrea.

Y el proceso de la percepción, a su vez dialógico, recursivo y holoscópico, produce y necesita una representación, concepto clave para este 
trabajo, porque constituye una síntesis cognitiva que se construye en forma de una imagen global, sentida a la vez como visión objetiva de las cosas reales y como apropiación subjetiva de esta visión objetiva, ya que toda percepción comporta un 'yo percibo' implícito. De esta manera el bucle perceptivo parte de los estímulos físicos recibido por las terminales sensoriales, codifica, transforma, organiza, traduce y remite a los sentidos una percepción global y coherente que integra todos los estímulos analizados y se proyecta al mundo exterior.

De esta manera es como sólo percibimos lo real a través de la representación, unidad fundamental de la percepción, del recuerdo y del sueño, porque todo pasa por ella, acto constitutivo idéntico y radical de lo real y lo imaginario, haciéndolos a la vez iguales, diferentes y opuestos, de ahí esta relación tan compleja, ya que los dos mundos antagonistas y complementarios parten de lo mismo: uno de la percepción y exploración empírico-racional de lo real, el otro del fantasma, del sueño, del mito; alimentándose recíprocamente y dejando siempre huella uno en el otro, interfiriendo incesantemente entre ellos (Morin, 1994, p. 116-34).

Para acceder a este complejo mundo está la base del lenguaje, vehículo cognitivo sin el cual no hay pensamiento ni cultura, que nos permite manifestar representaciones colectivas, conciencia colectiva e imaginario colectivo; y de nuevo se presenta el mismo principio, ya que el lenguaje está en nosotros y nosotros estamos en el lenguaje, o hacemos al lenguaje que nos hace. Sólo el lenguaje asegura a la vez la reproducción cultural y la solución individual de los problemas; sólo el lenguaje permite formular la desviación, la crítica, la contestación, permitiéndoles explicarse, constituyendo así una simplificación complejizante que permite utilizar una parte de la hipercomplejidad cerebral, construir / reconstruir una nueva complejidad discursiva y dialogar de este modo con la complejidad de lo real. Por eso es el lenguaje, herramienta privilegiada de comunicación, el que permite aquí sumergirse en un estudio de la memoria y la imagen en busca de una exploración del imaginario rielero.

Pero además, conviene subrayar, así como el pensamiento es inseparable del lenguaje, la conciencia lo es del pensamiento, y si algo caracteriza primordialmente el testimonio de Salvador, es la conciencia crítica que ha ido construyendo acerca del ferrocarril a lo largo de toda 
una vida; es por ello que sus experiencias cobran tal importancia, por la consciente reflexividad que las contextualiza, y no tanto por ellas mismas.

En el marco de los cuestionamientos que se plantean en la actualidad muchos proyectos de antropología e historia contemporánea, todo estriba en ver cómo el hombre y la mujer contemporáneos dotan de sentido subjetivo la experiencia, construyendo identidad a pesar de la falta de respuestas; porque en la época moderna cada vez es más evidente el desfase entre las dos útiles categorías que Koselleck establece para tematizar el tiempo histórico: espacio de experiencia y horizonte de expectativa (Koselleck, 1993, p. 333-43). Y es que a propósito de la asombrosa capacidad humana de vivir con las contradicciones, el reto estriba en intentar entender cómo se encuentran alternativas a pesar de tantas experiencias negativas que derivan de las transformaciones gestadas por la tan anhelada modernidad y de los dilemas y retos que el contexto sociocultural propone de manera permanente al individuo.

Entonces, si reconocemos a la identidad como un fenómeno que surge de la dialéctica entre individuo y sociedad, cabe ver de qué manera el cúmulo social de conocimiento se actualiza en esta historia individual. Pero ante todo, la identidad es un proceso activo y complejo, como también históricamente situado, $\mathrm{y}$, por tanto, de una enorme plasticidad. ¿Por dónde abordarla, entonces? En este caso, los conceptos trabajo y espacio me han parecido dos lentes de aproximación en los que detecto, en un principio, amplias posibilidades de observar y analizar este fenómeno que nos permite identificarnos como distinguirnos del otro.

El trabajo - contemplado aquí como toda aquella actividad transformadora que el sujeto desarrolla de manera regular a lo largo de una vida -, constructor de gratas e ingratas experiencias, que devienen gustos, necesidades e intereses, a lo largo del tiempo se convierte en un crisol de creencias, ideas, valores y tendencias, constituyéndose como el principal vínculo del sujeto con el sistema y la lógica moderna de la institucionalidad, lo que llamé la lógica del pensar, donde el tiempo, la razón y la proyección hacia el futuro se imponen.

Los espacios, marcos constantes de interacción social que sitúan al sujeto en un contexto más natural, le ofrecen opciones de libre elección de convivencia, participando a su vez en la construcción de aquellas 
creencias, ideas, valores y tendencias que lo caracterizan, pero desde la lógica del sentir, que proyecta hacia el pasado y la tradición, permitiendo una transformación permanente del yo, un devenir perenne del sujeto a partir de aquello por lo que opta.

¿Cómo vinculamos entonces los espacios con las identidades? Giménez ve en el territorio, un marco de inscripción de la cultura y por tanto una de sus formas de objetivación (Giménez, 1996, p. 14); para la identidad, fenómeno ante todo cultural, esto mismo representan los espacios. ${ }^{9}$ En el caso de México, donde las identidades tradicionales han ido perdiendo muchos de sus rasgos característicos, pero las identidades modernas no han fraguado como lo han hecho entre los estadounidenses, el análisis comparativo de Hiraoka resulta revelador. Efectivamente, sociedades que antes estaban muy definidas por su lengua, territorio, comida, ceremonias, costumbres, rituales... son progresivamente transformadas por la corriente llamada modernidad hacia una desterritorialización, la adopción de un nuevo idioma, y sobre todo, la imposición de la escuela y el trabajo como ejes a los que consagrar la existencia para el cultivo del individualismo, el materialismo y el consumismo.

Sin embargo, en el caso mexicano, como en otros del mundo, esta transformación no se ha dado como en los países industrializados. Aquí es éste un proceso, y por tanto, doblemente interesante de estudiar, como en este caso podemos hacer a nivel individual, local o 'micro'. Inmerso en este proceso de transformación, Salvador nos permite ver la negociación entre ambos polos identitarios en su propia persona, en la que, a pesar de vivir sumergido en la época de la gran expansión de las identidades modernas - en las que el trabajo se impone por encima de todo lo demás -, podemos observar algunos visos de asumida inadaptabilidad al esquema impuesto, así como las estrategias que toma para sobrellevar su época.

9 Al respecto, Jesse Hiraoka, con su trabajo sobre la identidad en Estados Unidos, establece una serie de diferencias muy claras entre 'identidades tradicionales' e 'identidades modernas'. Las primeras, apunta el autor, más vinculadas al espacio, tienden a proyectarse hacia el pasado, un pasado grupal; las segundas, más regidas por el tiempo, se proyectan hacia el futuro, un futuro individual (Hiraoka, 1996, p. 38-50). 
Ahora bien, ¿cómo vinculamos el trabajo a las identidades? En el estudio de las sociedades modernas, hemos visto por ejemplo con Hiraoka su importancia, pero desde la historia obrera, Samuel, a la hora de hablar de sistemas de representaciones, nos remite al testimonio oral, sosteniendo que son ya fundamentales nuevas materias primas y nuevos mapas de conocimiento para identificar los rostros de la multitud y así, eslabonar lo particular con lo general, el momento aislado con la larga duración (Samuel, 1984, p. 16-38).

Considerando que el trabajo rige tantas vidas y condiciona tantos otros factores como el familiar, una sociedad como la nuestra - donde el orgullo profesional y el trabajo como acto creativo ya no juegan un papel tan importante -, demanda que estudiemos la búsqueda de las clases subordinadas por construir un proyecto alternativo de sociedad: "descubrir tradiciones obreras que se renuevan y recrean como prefiguración de la nueva sociedad a la que se aspira, sistematizarlas como aspectos de una historia por escribir en la que se identifique y reconozca la clase en su desarrollo, resulta tarea impostergable" (Novelo, 1986, p. 129). Finalmente, tenemos la presencia de obreros como grupo social y a veces como clase, pero casi nunca como seres humanos (Novelo y Sariego, 1984, p. 51).

Aquí es donde los testimonios audiovisuales, como los orales, se develan como alternativa: en la comprensión de las representaciones culturales del ferrocarril que el imaginario social se ha apropiado de manera selectiva, como lo hace la memoria. Porque lo que el cine construye, como lo hace la memoria de la gente, permite lo que Ferro llamó un contra-análisis de la sociedad ${ }^{10} \mathrm{O}$, en otras palabras, el análisis de la otra cara de la sociedad, esa otra cara donde está lo vivido, lo sentido, lo sufrido y no sólo lo pensado; y quién mejor que las imágenes en movimiento para narrarnos este otro mundo más cercano al imaginario-real del común de la gente. ${ }^{11}$

10 Porque "hace caer las máscaras, muestra el reverso de una sociedad, sus lapsus" (Ferro, 1979, p. 245).

11 "Si vivimos intensamente con el espíritu, sin por ello vivirlos realmente, las vidas, sentimientos, amores, deseos, temores, odios de nuestros héroes de las películas es porque en nosotros se pone en funcionamiento una formidable máquina de proyección / identificación, haciendo de nuestra participación en la película un momento formidable de comprensión de los demás; comprendemos en el interior al 
Inmersos en el mundo de la llamada modernidad, nos encontramos sumergidos en un proceso sin fin; como diría Balandier, "jamás se es moderno, se está siempre en vías de serlo" (Balandier, 1988, p. 142). La retórica del cambio por el cambio, nos ha conducido hacia una cultura de lo efímero en la que impera el tiempo sobre el espacio y, con ello, la incertidumbre sobre un porvenir imprevisible. Es frente a esta pluralidad de niveles de realidad que resurge la importancia de la exploración del imaginario, porque es éste el que confiere al sujeto una representación narrable de su vida personal. Y, como hemos visto, no podemos hablar de imaginario sin hablar de memoria, a su vez ingrediente principal del relato y la historia de vida, fuentes de información de primera importancia para estudiar el imaginario.

Ante el escenario de contradicciones engendrado por la modernidad, el imaginario se presenta como más necesario que nunca; es lo que alimenta toda vida personal y toda vida en colectividad; conformado por todas las imágenes que componemos a partir de la aprehensión sobre todo de nuestro cuerpo y nuestro deseo, como de nuestro entorno y nuestras relaciones con lo otros, se nutre del capital cultural recibido y adquirido y de las elecciones que hacemos a partir de él para proyectarnos en un porvenir próximo, a la vez que reconocernos en un pasado cercano.

Y como las imágenes están siempre entretejidas a los espacios, con esta debilitación de la conciencia de continuidad provocada por el imperio de la modernidad, el espacio imperante en el imaginario es hoy el de las fugas. De esta manera surge la sensación de malestar ocasionada por el vértigo de la impresión de vivir sólo el presente, que aunada a esta ilusión de un mundo sin duración, nos ha llevado a un apogeo del orden del deseo, convirtiendo la modernidad en una aventura de muy interesante exploración a través de lo que Balandier llama el desvio antropológico, esa forma de vida que te transforma a medida que conoces los procesos de la gran transformación que nos envuelve de manera constante.

vagabundo, al gánster, el asesino, mientras que en la vida normal todos los puntos de identificación se encuentran cortados. Sin duda nunca somos tan capaces de comprensión del los demás como en el cine" (Morin, 1994, p. 158). 
De ahí la doble dificultad de desprenderse de los acontecimientos y ver los movimientos lentos enmarcados por la vida cotidiana, las mentalidades, el folclor y la cultura. Finalmente, como diría Duby, el acontecimiento no es más que un adoquín lanzado a un charco. Frente al documento y la memoria de los textos, tradicionalmente guardianes de lo excepcional, el sujeto y la memoria humana se develan como las matrices donde se conservan las cosas más modestas, las encargadas de construir aquellos lentos movimientos que quisimos aprehender en este estudio.

Las nuevas preguntas, las nuevas fuentes, las nuevas miradas nos han conducido a través de la complejidad y la naciente transdisciplina hacia una nueva racionalidad. En ella, el ser humano y la toma de decisiones se construyen a partir de la imagen del futuro y la memoria del pasado, conformando un ser-en-devenir permanente. Dentro del pensamiento complejo, el papel de la percepción y la imaginación desde la investigación está siendo revalorado como fundamental en el proceso de conocimiento; y es que para acercarse a la complejidad e incertidumbre que enmarañan la dinámica histórica, al orden, desorden y nuevas organizaciones que deconstruyen y reconstruyen sin cesar el mundo, el enfoque transdisciplinar todavía puede y debe enseñarnos mucho más.

He ahí también la revaloración de la narrativa, de la arquitectura del relato y la importancia de mirar la historia con la antropología, así como la antropología con la historia, y también con la literatura, la filosofía y la lingüística. Porque relacionando sucesos, el relato, cercano a la metáfora, crea una trama, construyendo sentido; así es como la Historia con mayúsculas se disuelve en infinitas historias, dibujando y cartografiando experiencias únicas. Y partiendo de que es precisamente el relato el guardián del tiempo, privilegio por su particular interés este binomio constituido por la narración y el tiempo, tan profusamente escudriñado por Ricoeur.

Es él, retomando a San Agustín, quien nos recuerda el carácter triple del presente: el presente de lo pasado, contenido en la memoria; el presente de lo presente, en la visión; y el presente de lo futuro, en la expectación. De esta manera, la imagen es a la vez huella del pasado y signo del futuro, lo que a través de la fenomenología del tiempo lo conduce a afirmar que la referencia por huellas y la metafísica se cruzan en la temporalidad. 
Por tanto, "la antropología histórica se ocupa de transferir a la distancia histórica el modo de entrañamiento dado a la antropología por la distancia geográfica y en reconquistar, más allá de la cultura erudita, la costumbre, el gesto, lo imaginario, en una palabra: la cultura popular" (Ricoeur, 1995, p. 190). Porque es este universo simbólico el que aporta el orden para la aprehensión subjetiva de la experiencia biográfica, y es así como "el lenguaje realiza un mundo, en el doble sentido de aprehenderlo y producirlo" (Berger y Luckman, 1995, p. 193).

Y si finalmente la identidad es un fenómeno que surge de la dialéctica entre el individuo y la sociedad, en un universo que ante todo ni es estable ni armónico, sino que es movimiento constante, derivamos que es gracias a esta interacción permanente que nos movemos entre el orden, el desorden y las nuevas organizaciones, subsistiendo el orden gracias al desorden. De manera que si la historia tradicional, de enfoque holista y abanderada del lenguaje escrito nos enseñaba que la suma de las partes era el todo y que éste era la suma de las partes, a través del pensamiento complejo y todos sus antecedentes, donde el lenguaje escrito es engarzado con el oral y también con el pensado, el todo puede ser menos que las partes.

Si la historia inmortaliza el pasado, la oralidad le da vida y movimiento, por eso coincido en ver la realidad como discurso, porque existe en la medida en que es nombrada, habiendo tantas realidades como interpretaciones, ya que el discurso se modifica y actualiza constantemente. De ahí la importancia de ver el pasado desde sus propias producciones de sentido y desde las coyunturas en las que el discurso se modifica y actualiza, porque en ellas está la producción de sentido. Es así como lo que tenemos son versiones verosímiles, ni únicas ni verdaderas, pero sí reales, ya que el tiempo sólo existe en la medida en que hacemos uso de él para referirnos al pasado.

Por eso al tomar al sujeto como texto, él constituye el punto de partida de reflexión y el de llegada; porque el yo se revela como ilusión, como construcción cultural, como proyección de un deseo, pero este deseo depende de nosotros y no nosotros de él; de ahí la importancia de la memoria corta frente a la memoria larga, de la inmanencia frente a la trascendencia. Precisamente ahí está el reto, en deslizarse de la memoria larga, o lo que pensamos, a la memoria corta, o lo que sentimos. 
La relación entre la realidad y el imaginario social sólo podemos aprehenderla a través del discurso, a través de las representaciones que hacemos de ella, y ahí el sujeto aparece como una matriz privilegiada de construcción, deconstrucción y reconstrucción permanente de la experiencia presente, a partir del pasado vivido y el futuro soñado. Es en el análisis del sujeto como texto, del diálogo que mantiene de manera permanente con los tiempos y los espacios, donde podemos encontrar las relaciones y la interacción entre organización y desorganización que nos permiten pervivir a la vez al caos y al sistema.

\section{Referencias bibliográficas, hemerográficas y videográficas}

BALANDIER, George. Modernidad y poder: el desvío antropológico. BarceIona: Júcar Universidad, 1988.

BERGER, Peter L.; LUCKMAN, Thomas. La construcción social de la realidad. Buenos Aires: Amorrortu, 1985.

CORADINI, Lisabete; ROCA, Lourdes. El uso de la imagen en antropología social. In: PÉREZ-TAYLOR, Rafael. (coord..). Aprender-comprender la antropología. México: Grupo Patria Cultural, 2000.

DUBY, George. La historia continua, Madrid: Debate, 1992.

FERRO, Marc. El cine, ¿un contraanálisis de la sociedad?. Hacer la historia (3). Barcelona: Laia, 1979.

GIMÉNEZ, Gilberto. Territorio y cultura. Estudios sobre las culturas contemporáneas. Universidad de Colima, II Epoca, v. 11, n. 4, Dic. 1996, p. 9-30.

HIRAOKA, Jesse. La identidad y su contexto dimensional. In: Identidad: III Coloquio Paul Kirchhoff. México: UNAM-IIA-DGAPA, 1996, p. 38-50.

IBÁÑEZ, Jesús. El regreso del sujeto. México: Siglo XXI, 1994.

KOSELLECK, Reinhart. Futuro pasado: Para una semántica de los tiempos históricos. Barcelona: Paidós Básica 61, 1993.

LIZARRAGA, Xavier. Las diferentes culturas y las culturas de diferencia. Cuicuilco, v. 5 n. 12, Nueva Época, enero-abril 1998, p. 245-54.

MORIN, Edgar. El método Il: la vida de la vida, Barcelona: Cátedra, 1994. MORIN, E. Introducción al pensamiento complejo. Barcelona: Gedisa, 1996. MRAZ, John. Video e historia obrera en México: historia oral, video-historia y fotografía. Voces y culturas (5). Barcelona: 1993, p. 24-44. 
NOVELO, Victoria. La cultura obrera, una contrapropuesta cultural. El obrero mexicano (5), México: Siglo XXI/IIS-UNAM, 1986.

NOVELO, Victoria; SARIEGO, Juan Luis. Algunas cuestiones de método para el estudio de la clase obrera. In: Historia del movimiento obrero. Tomo I. México: BUAP, 1984.

RICOEUR, Paul. Tiempo y narración I. Configuración del tiempo en el relato histórico. México: Siglo XXI, 1995.

ROCA, Lourdes. Km. C-62: Un nómada del riel. México: Plaza y Valdés / Instituto Mora / CONACyT-FONCA (libro y documental en video), 2000(a). . El ferrocarril y las imágenes en movimiento: ¿por un México nuevo? In: NOVELO, Victoria; RAMOS, Sergio López (coord.), Etnografía de la vida cotidiana. México: Porrúa Hnos., 2000(b).

SAMUEL, Raphael. Historia popular y teoría socialista. Barcelona: Grijalbo/ Crítica, 1984.

Resumen: El estudio constituye una historia de lo que el ferrocarril ha representado para la gente, a través sus recuerdos y representaciones; por ello la memoria y la producción cultural visual fueron los principales referentes de los que se nutrió esta investigación. Si bien en este artículo no se darán a conocer los resultados de la investigación, que pueden consultarse en las publicaciones que ya los contienen, sí considero importantes algunas reflexiones que quiero aquí destacar y que surgieron al final del trabajo.

Palabras llave: ferrocarriles de México; identidad; testimonios audiovisuales.

O ESPAÇO VIVIDO COMO EIXO ARTICULADOR DO BINÔMIO TEMPO-NARRAÇÃO

Resumo: O estudo constitui uma história do que a estrada de ferro representa para as pessoas, através de suas lembranças e representações; por isso a memória e a produção cultural visual foram os principais referentes de que se nutriu essa pesquisa. Embora nesse artigo não se dêem a conhecer os resultados da pesquisa, que podem ser consultados nas publicações que já os contêm, considero importantes algumas reflexões que quero destacar aqui e que surgiram no final do trabalho.

Palavras-chave: estradas de ferro do México; identidade; testemunhos audiovisuais. 